\title{
Non-Invasive Mechanical Ventilation in Children with Previous Unsuccessful Weaning from Respiratory Therapy
}

\author{
Olha Filyk
}

\begin{abstract}
The objective of the research was to establish the impact of diaphragm-protective mechanical ventilation on the rate of successful weaning from invasive and non-invasive mechanical ventilation in children with acute respiratory failure.

Materials and Methods. We conducted a prospective, observational cohort study. Seventy-eight patients were randomly divided into 2 groups: patients of Group I received lung-protective mechanical ventilation; patients of Group II received diaphragm-protective + lung-protective mechanical ventilation. For age-specific data analysis, patients were divided into age subgroups: the $1^{\text {st }}$ subgroup included children being 1 to 12 months old; the $2^{\text {nd }}$ age subgroup comprised children being 12 to 36 months old. We started respiratory support in both groups with invasive mechanical ventilation and when patients met the criteria, we weaned them. We confirmed successful weaning, when patients had no need to be mechanically ventilated within next 48 hours, otherwise, they were intubated again. Before the second trial to wean, patients in Group I were simply extubated, while patients in Group II received non-invasive mechanical ventilation. The primary endpoint was the rate of successful weaning from mechanical ventilation in the first trial. The secondary outcomes were complications, namely reintubation rate, tracheostomy rate and death.

Results. We found a significant difference in the primary outcome for the $1^{\text {st }}$ age subgroup: there were $72.4 \%$ in Group I vs. $52.6 \%$ in Group II successfully weaned patients $(p=0.04)$. No significant difference in the primary outcome was observed in the $2^{\text {nd }}$ age subgroup: there were $80 \%$ in Group I vs. $82.3 \%$ in Group II successfully weaned patients $(p=0.78)$. There were significant differences in the secondary outcomes between groups in the $1^{\text {st }}$ age subgroup, namely reintubation rate was seen in $9.1 \%$ patients of Group I vs. $36.8 \%$ patients of Group II ( $p=0.05)$; death happened in $18.2 \%$ cases in Group I vs. no cases in Group II $(p=0.01)$. There were no differences in tracheostomy rate in the $1^{\text {st }}$ age subgroup and there were no differences in the secondary outcomes between groups in $2^{\text {nd }}$ age subgroup.

Conclusions. Diaphragm-protective mechanical ventilation significantly reduced the incidence of successful weaning from invasive mechanical ventilation; however, it increased the incidence of successful weaning from non-invasive mechanical ventilation, and, significantly decreased the mortality rate in the $1^{\text {st }}$ age subgroup, while in the $2^{\text {nd }}$ age subgroup, it had no impact on the incidence of successful weaning from invasive mechanical ventilation and mortality rate.
\end{abstract}

\section{Keywords}

children; non-invasive mechanical ventilation; weaning from mechanical ventilation

Danylo Halytsky Lviv National Medical University, Lviv, Ukraine

*Corresponding author: filyk_olha@meduniv.lviv.ua 
Problem statement and analysis of the latest research

Weaning from mechanical ventilation (MV) can be defined as the gradual reduction in respiratory support, assigning a spontaneous breathing time to let the child take responsibility for an acceptable gas exchange [3]. The term extubation failure (EF) represents a set of conditions that determine the need for reintubation and MV restoration within the first 24-72h after the removal of the endotracheal tube $[3,4]$. Non-invasive mechanical ventilation (NIMV) offers an alternative to intubation with possibility of providing MV in the treatment of acute respiratory failure in infants and children [1] and helps restore diaphragm function as soon as possible in case of good patient-machine synchronization. However, medical staff have to remember about one of the important problems of NIMV poor adherence to NIMN in some age groups of children, as it can contribute to poor outcomes and may lead providers to perform more invasive alternatives [2].

The objective of the research was to establish the impact of diaphragm-protective MV on the rate of successful weaning from invasive and non-invasive $\mathrm{MV}$ in children with acute respiratory failure.

\section{Materials and Methods}

We conducted a prospective, observational cohort study at the Department of Anesthesiology and Intensive Care of Lviv Regional Children's Clinical Hospital "OHMATDYT" and enrolled 80 patients being 1 to 36 months old. We included patients with acute respiratory failure who were mechanically ventilated for more than 3 days.

Exclusion criteria for the study were as follows: the refusal of the patient's legal representatives to participate in the study at any of its stages, the patient's agonizing state upon admission. Two patients were excluded from data analysis as they did not meet inclusion criteria. Seventy-eight patients were randomly divided into 2 groups: patients of Group I received lung-protective MV; patients of Group II received diaphragm-protective MV in ad- dition to lung-protective MV. For age-specific data analysis, patients were divided into age subgroups: the $1^{\text {st }}$ age subgroup $(n=41)$ included children being 1 to 12 months old; the $2^{\text {nd }}$ age subgroup $(n=37)$ included children being 12 to 36 months old.

We started respiratory support in both groups with invasive MV (via the endotracheal tube) and when patients met the criterion (falling down severity of acute respiratory failure (ARF) was confirmed by clinical, laboratory and instrumental data), we weaned them (patients were simply extubated and received oxygen supply via a face mask as long as they needed it to achieve oxygen saturation ( $\mathrm{SpO} 2)$ more than $95 \%$.

Respiratory therapy and monitoring of respiratory mechanics were performed by means of the ventilators "Hamilton-C1", "Hamilton-C3", "VELA" in pressure-controlled ventilation modes (PSIMV, PSIMV+, PSV). We took into account "Recommendations for mechanical ventilation of critically ill children from the Pediatric Mechanical Ventilation Consensus Conference (PEMVECC), 2016", lungprotective strategy, the aim of which was to limit a tidal volume less than $6 \mathrm{ml} / \mathrm{kg}$ body weight, plateau pressure (Pplat) less than $28 \mathrm{~cm} \mathrm{H} 2 \mathrm{O}$, delta pressure less than $10 \mathrm{~cm} \mathrm{H} 20$, and chose such inspiratory time (TIn), that at least two RCexp (exhalation constants) remained on exhalations.

The effectiveness of respiratory therapy was controlled with pulse oximetry ( $\mathrm{SpO} 2)$, acid-base balance blood test ( $\mathrm{paO} 2, \mathrm{paCO} 2, \mathrm{SaO} 2)$ and $\mathrm{paO} 2 / \mathrm{FiO} 2$ ratio calculation.

The aim of respiratory therapy was to maintain $88 \%-95 \%$ of blood saturation, paO2 over $55-80$ $\mathrm{mm} \mathrm{Hg}$, paCO2 below 55-60 mm Hg. Diaphragmprotective strategy of MV means the maintenance of spontaneous diaphragmatic activity in patients (with no muscle relaxant administration in case of sufficient oxygenation level and good patient-ventilator synchronization), with diaphragmatic thickening fraction over $15 \%$ with amplitude of movements between 8 and $10 \mathrm{~mm}$ on diaphragm ultrasound.

The criteria for weaning from MV were as follows: spontaneous respiratory rate and minute volume ventilation more than $75 \%$ and less than $125 \%$ of normal ranges for age, the presence of sponta- 
neous cough and swallowing reflexes, regression of hypoxemia severity (we took into account achievement of $\mathrm{SpO} 2$ over $95 \%$ and $\mathrm{paO} 2$ over $60 \mathrm{~mm} \mathrm{Hg}$ with $\mathrm{FiO} 2$ less than $40 \%$, paO2/FiO2 ratio over 250), clinical improvement of patient's state. Apart from these, in Group II, patients had to achieve enough level of diaphragmatic activity.

We confirmed successful weaning, when patients had no need to be mechanically ventilated in next 48 hours after weaning. Those patients who needed MV up to 48 hours after extubation were intubated and mechanically ventilated. Before the second trial to wean, patients of the $1^{\text {st }}$ age subgroup in Group I were simply extubated, while patients in Group II received NIMV (we included both NIMV - via a nasal mask and nasal cannulas) with PSV mode and at least PEEP $=8 \mathrm{~cm} \mathrm{H}_{2} \mathrm{O}$ and $\mathrm{PS}=12-14 \mathrm{~cm} \mathrm{H}_{2} \mathrm{O}$ for the first time; in next titration this supported achieving as little as possible respiratory muscles load. The reason why we did not use NIMV in the $2^{\text {nd }}$ age subgroup was usual inability to achieve patient cooperation with medical team during NIMV and $100 \%$ need to be converted to invasive MV.

The primary endpoint was the rate of successful weaning from MV in the first trial. The secondary outcomes were complications, namely reintubation rate, tracheostomy rate and death. We calculated the rate of successful weaning using NIMV in the $1^{\text {st }}$ age subgroup and total duration of MV (summing the time of the first, second and all next trials of MV till successful weaning) in Group I and Group II as well.

Statistical analysis of the study results was performed using MS Excel 2017 with the calculation number (\%), median [IQR - interquartile range], mean value taking into account the standard deviation $(\mathrm{M} \pm \sigma)$, the level of significance $\mathrm{p}$.

\section{Ethical Approval}

All patients' relatives or their legal representatives received informed consent to participate in the study.

The study was approved by the Bioethics Commission of Danylo Halytsky Lviv National Medical University, protocol No 1, January 30, 2018, and conducted according to WMA Declaration of Helsinki.

\section{Results}

Out of 80 patients included in the study during 2016-2020, 78 patients were randomized, 42 into Group I (22 patients in the $1^{\text {st }}$ age subgroup and 20 patients in the $2^{\text {nd }}$ age subgroup) and 36 into Group II (19 patients in the $1^{\text {st }}$ age subgroup and 17 patients in the $2^{\text {nd }}$ age subgroup). There were no differences between the groups at baseline in terms of age, height, weight and severity of multiple organ dysfunction syndrome according to the Pediatric Multiple Organ Dysfunction Score (P-MODS) (Table 1). After randomization, we made the analysis of nosological structure of the patients admitted and found that in the $1^{\text {st }}$ age subgroup, there were $58 \%$ of patients with type I (hypoxemic) ARF due to pneumonia and $42 \%$ of patients with type I + type II (hypoxemic-hypercapnic) ARF due to pneumonia in combination with bronchitis/bronchiolitis, whereas in the $2^{\text {nd }}$ age subgroup, there were $82 \%$ of patients with type I ARF and $18 \%$ of patients with type I + type II ARF. Type I ARF occurred due to severe pneumonia; type I + type II ARF developed due to coexistence of severe pneumonia and acute obstructive bronchitis/bronchiolitis. There were no significant differences in the etiology of ARF between Group I and Group II in the $1^{\text {st }}$ and $2^{\text {nd }}$ age subgroups. All listed above gave us the opportunity to assume that our results are statistically significant.

We found a significant difference in the primary outcome for the $1^{\text {st }}$ age subgroup: in Group I, there were $16(72.4 \%)$ successfully weaned patients vs. $10(52.6 \%)$ successfully weaned patients in Group II ( $\mathrm{p}=0.04)$. No significant difference in the primary outcome was observed in the $2^{\text {nd }}$ age subgroup: in Group I, there were $16(80 \%)$ successfully weaned patients vs. $14(82.3 \%)$ successfully weaned patients in Group II ( $\mathrm{p}=0.78)$.

There were significant differences in the secondary outcomes between groups in the $1^{\text {st }}$ age subgroup (Table 2), namely reintubation rate was seen in $2(9.1 \%)$ patients of Group I vs. 7 (36.8\%) 
Table 1. Patient characteristics.

\begin{tabular}{lcccc}
\hline Parameters & Age subgroup & Group I $(\mathrm{n}=42)$ & Group II $(\mathrm{n}=36)$ & $\mathrm{p}^{\mathrm{a}}$ \\
\hline \multirow{2}{*}{ Age, month } & $1^{\text {st }}$ & $2[1.5 ; 8.5]$ & $2[1.3 ; 6.7]$ & 0.73 \\
& $2^{\text {nd }}$ & $21[14.5 ; 19]$ & $20[13 ; 18.75]$ & 0.24 \\
Weight, $\mathrm{kg}$ & $1^{\text {st }}$ & $4[2.9 ; 4.5]$ & $4[3.1 ; 4.4]$ & 0.21 \\
& $2^{\text {nd }}$ & $11[9.8 ; 12.1]$ & $11[10.3 ; 11.8]$ & 0.23 \\
Height, cm & $1^{\text {st }}$ & $53[52 ; 56]$ & $54[52 ; 56]$ & 0.44 \\
& $2^{\text {nd }}$ & $80[78 ; 82]$ & $82[80 ; 85]$ & 0.23 \\
BMI, $\mathrm{kg} / \mathrm{m}^{2}$ & $1^{\text {st }}$ & $14.23[11.4 ; 15.1]$ & $13.7[11.1 ; 14.9]$ & 0.54 \\
& $2^{\text {nd }}$ & $17.2[14.1 ; 18.3]$ & $16.4[13.9 ; 17.9]$ & 0.26 \\
P-MODS, points & $1^{\text {st }}$ & $5.2 \pm 0.3$ & $4.1 \pm 0.4$ & 0.18 \\
& $2^{\text {nd }}$ & $4.7 \pm 0.5$ & $4.2 \pm 0.7$ & 0.22 \\
\hline
\end{tabular}

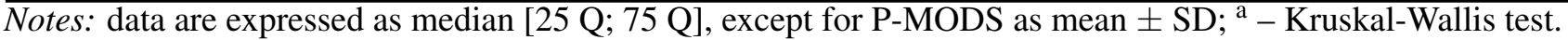

patients of Group II ( $\mathrm{p}=0.05)$; death happened in $4(18.2 \%)$ cases in Group I vs. no cases in Group II ( $\mathrm{p}=0.01)$. There were no differences in tracheostomy rate in the $1^{\text {st }}$ age subgroup: $9.1 \%$ in Group I vs. $10.5 \%$ in Group II ( $\mathrm{p}=0.28)$. There were no differences in the secondary outcomes between groups in the $2^{\text {nd }}$ age subgroup, namely reintubation rate was observed in $4(20 \%)$ patients in Group I vs. $3(17.6 \%)$ patients in Group II ( $\mathrm{p}=0.15)$; there were neither tracheostomy procedures nor death incidences in Group I and Group II.

NIMV was used as a step for weaning from MV in all first time unsuccessfully weaned patients in Group II of the $1^{\text {st }}$ age subgroup ( 7 patients) before the second trial to extubate. There were $5(71.4 \%)$ patients who were successfully weaned within next 3-4 days of NIMV and 2 (28.6\%) patients were intubated again and returned to invasive MV. Those patients who failed NIMV experienced one more NIMV in few days later and after this, they were successfully weaned from MV.

We found no significant difference in the total duration of MV, as the time till complete liberation from MV: in the $1^{\text {st }}$ age subgroup, 17 [7; 22] days in Group I vs. 11 [5.25; 15] days in Group II ( $\mathrm{p}=0.08)$; in the $2^{\text {nd }}$ age subgroup, $12[2 ; 27]$ days vs. $5[2$; 11.75 ] days $(\mathrm{p}=0.18)$.

The current study showed that diaphragmprotective MV could significantly reduce the incidence of successful weaning from invasive MV; however, it could increase the incidence of successful weaning from NIMV and, in addition, decrease the mortality rate in the $1^{\text {st }}$ age subgroup of patients. On the other hand, diaphragm-protective MV had no impact on the incidence of successful weaning from invasive MV and mortality rate in the $2^{\text {nd }}$ age subgroup.

\section{Discussion}

In pediatrics, the experience of weaning patients from NIMV is limited, as the information available is obtained from uncontrolled studies and case series involving few patients. There was the only prospective study involving the pediatric population conducted by Harikumar (2009) [5], where noninvasive technology of weaning 80 patients from $\mathrm{MV}$ using CPAP $5 \mathrm{~cm} \mathrm{H}_{2} \mathrm{O}$ were compared. In addition, Yaman A et al. [6] and Haut C [7] reported that non-invasive ventilation (NIV) was more effective in preventing reintubation when used early in patients at high risk of $\mathrm{EF}$ as compared to its use as a rescue therapy in patients with established respiratory failure. Moreover, the authors observed that the reduction in the respiratory rate (RR) and $\mathrm{FiO}_{2}$ after $6 \mathrm{~h}$ was associated with the success of NIMV. Likewise, S Rolim et al. [8] agreed that both measurements, combined with $\mathrm{pH}$ and underlying pathology, are criteria to be considered when predicting the effectiveness of NIMV in pediatric patients. 
Table 2. Primary outcome and detailed analysis of study results.

\begin{tabular}{lcccc}
\hline Parameters & $\begin{array}{c}\text { Age } \\
\text { subgroup }\end{array}$ & $\begin{array}{c}\text { Group I } \\
(\mathrm{n}=42)\end{array}$ & $\begin{array}{c}\text { Group II } \\
(\mathrm{n}=36)\end{array}$ & $\mathrm{p}^{\mathrm{a}}$ \\
\hline Presence of the primary outcomes, $\mathrm{n}(\%)$ & $1^{\text {st }}$ & $16(72.4 \%)$ & $10(52.6 \%)$ & 0.04 \\
& $2^{\text {nd }}$ & $16(80 \%)$ & $14(82.3)$ & 0.78 \\
Reintubation rate, $\mathrm{n}(\%)$ & $1^{\mathrm{st}}$ & $2(9.1 \%)$ & $7(36.8 \%)$ & 0.05 \\
Tracheostomy rate, $\mathrm{n}(\%)$ & $2^{\text {nd }}$ & $4(20 \%)$ & $3(17,6 \%)$ & 0.15 \\
& $1^{\text {st }}$ & $2(9.1 \%)$ & $2(10.5 \%)$ & 0.28 \\
Mortality rate, $\mathrm{n}(\%)$ & $2^{\text {nd }}$ & $0(0 \%)$ & $0(0 \%)$ & 1 \\
& $1^{\text {st }}$ & $4(18.2 \%)$ & $0(0 \%)$ & 0.01 \\
\hline
\end{tabular}

Notes: data are expressed as a number (\%), ${ }^{\mathrm{a}}-\chi^{2}$ test.

Bandyopadhyay A et al. [9] have recently reported beneficial effects of NIV during decannulation in a group of select pediatric patients with severe upper airway obstruction, as well as in the treatment of respiratory failure after decannulation. Nevertheless, the integration of NIMV in weaning requires preset criteria for initiation and failure, which are not yet fully defined and validated in pediatrics. In the future, the transitional use of NIV in weaning from MV will be considered successful if it facilitates weaning and/or prevents reintubation [10].

Our current study has several limitations as well. Firstly, neither the primary outcome assessor nor medical staff taking care for patients, could be blinded to group allocation due to the nature of the study; secondly, we did not use NIMV in the $2^{\text {nd }}$ age subgroup of patients due to well-known problems of their cooperation with medical staff during this time; thirdly, the number of patients, who were included in the study, have to be enlarged to try to achieve significant differences in the secondary outcomes.

\section{Conclusions}

Diaphragm-protective MV could significantly reduce the incidence of successful weaning from invasive MV; however, it could increase the incidence of successful weaning from NIMV and, in addition, decrease the mortality rate in the $1^{\text {st }}$ age subgroup of patients. On the other hand, diaphragm-protective
MV had no impact on the incidence of successful weaning from invasive MV and the mortality rate in the $2^{\text {nd }}$ age subgroup.

\section{Prospects of Further Researches}

Further studies are required to evaluate whether NIMV can improve the outcome in all age subgroups of mechanically ventilated children.

\section{Informed Consent}

Patients' informed consent was obtained for all included patients.

\section{Conflict of Interest}

The author stated no conflict of interest.

\section{Financial Disclosure}

Danylo Halytsky Lviv National Medical University provided us with kits for acid-base balance blood tests.

\section{References}

[1] Fedor KL. Noninvasive Respiratory Support in Infants and Children. Respir Care [Internet]. 2017 Jun 25; 62(6):699-717. DOI: https : / / doi.org/10.4187/respcare.05244 [PMid:28546373] 
[2] Hawkins SMM, Jensen EL, Simon SL, Friedman NR. Correlates of Pediatric CPAP Adherence. J Clin Sleep Med [Internet]. 2016 Jun 15;12(06):879-84. DOI: https://doi.org/10.5664/ jcsm.5892 [PMid:27092702 PMCid:PMC4877321]

[3] Nascimento MS, Rebello CM, Vale LAPA, Santos É, Prado C do. Spontaneous breathing test in the prediction of extubation failure in the pediatric population. Einstein (Sã o Paulo) [Internet]. 2017 Jun 15;15(2):162-6. DOI: https: / / doi .org/ $10.1590 / \mathrm{s} 1679-45082017 \mathrm{a} 03913$ [PMid:28767913 PMCid:PMC5609611]

[4] Bonora JP, Frydman J, Retta A, Canepari A. Post-extubation non-invasive ventilation in the pediatric intensive care unit: a multicenter study. Arch Argent Pediatr. 2018;116(5):333339. DOI: https: / / doi .org/10.5546/ aap. 2018 .eng. 333

[5] Harikumar G, Egberongbe Y, Nadel S, Wheatley E, Moxham J, Greenough A, et al. Tension- Time Index as a Predictor of Extubation Outcome in Ventilated Children. Am J Respir Crit Care Med [Internet]. 2009 Nov 15;180(10):9828. DOI: https://doi.org/10.1164/ rccm.200811-17250C [PMid:19696443 PMCid:PMC2778157]

[6] Yaman A, Kendirli T, Ö dek Ç , Ateş C, Taşyapar N, Gü neş M, et al. Efficacy of noninvasive mechanical ventilation in prevention of intubation and reintubation in the pediatric intensive care unit. J Crit Care [Internet]. 2016 Apr 15; 32 (10): 17581. DOI: https://doi.org/10.1016/ j.jcrc.2015.12.013 [PMid:26795440]

[7] Haut C. Pediatric Noninvasive Ventilation. J Pediatr Intensive Care [Internet]. 2015 Aug 28;04(02):121-7. DOI: https:// doi.org/10.1055/s-0035-1556754 [PMid:31110861 PMCid:PMC6513139]
[8] S. Rolim D, Galas FRB, Faria LS, Amorim EF, Regenga MM, Troster EJ. Use of Noninvasive Ventilation in Respiratory Failure After Extubation During Postoperative Care in Pediatrics. Pediatr Cardiol [Internet]. 2020 Apr 5;41(4):729-35. DOI: https://doi. org/10.1007/s00246-020-02290-6 [PMid:32025758 PMCid:PMC7223835]

[9] Bandyopadhyay A, Cristea AI, Davis SD, Ackerman VL, Slaven JE, Jalou HE, et al. Retrospective Analysis of Factors Leading to Pediatric Tracheostomy Decannulation Failure. A Single-Institution Experience. Ann Am Thorac Soc [Internet]. 2017 Jan 5;14(1):70-5. DOI: https://doi.org/ $10.1513 /$ AnnalsATS . 201607-5530C [PMid:27768853 PMCid:PMC5461993]

[10] dos Santos Bacci SLL, Johnston C, Hattori WT, Pereira JM, de Oliveira Azevedo VMG. Mechanical ventilation weaning practices in neonatal and pediatric ICUs in Brazil: the Weaning Survey-Brazil. J Bras Pneumol [Internet]. 2020 Jan 5;46(1):e20190005e20190005. DOI: https://doi.org/ $10.36416 / 1806-3756 / e 20190005$ [PMid:32215452]

Received: $2020-08-18$

Revised: 2020-09-04

Accepted: 2020-09-17 